TIP Periodica Polytechnica

Social and Management Sciences

22(2), pp. 149-155, 2014

DOI: 10.3311/PPso.7626

Creative Commons Attribution (i)

RESEARCH ARTICLE

\section{A Model for the Relationship between Work Attitudes and Beliefs of Knowledge Workers with Their Turnover Intention}

\author{
Reza Rasouli / Mehdi Rashidi / Mojgan Hamidi
}

ReCeived 16 July 2014; ACCePted 10 November 2014

\begin{abstract}
Growing of science and technology and extending of knowledge-based organizations, the development and maintenance of high-performance knowledge workers with high-potential will be very critical institutionally and nationally. This study aimed to explore the predictability of knowledge workers' intention to stay through their work attitudes and beliefs including believe in reliability of managers, job satisfaction and organizational commitment in the context of the academic community of Iran. Standard questionnaires were used to measure the variables. In order to gather data, stratified random sampling of faculty members in colleges and higher education institutions in South Khorasan, was accomplished. The results obtained in method of path analysis with AMOS software show that believe of knowledge workers in reliability of managers and organizational commitment can anticipate intend to stay. Among them, trust in management has the strongest indirect effect on the intention to stay. Also, job satisfaction through organizational commitment can predict the intention to stay of knowledge workers.
\end{abstract}

\section{Keywords}

trust in management $\cdot$ knowledge workers $\cdot$ turnover intention - retention $\cdot$ universities \& higher education institutions

\section{Reza Rasoul}

\section{Mehdi Rashidi}

Department of Management, Economics and Accounting, Payame Noor University, PO BOX 19395-3697 Tehran, Iran

\section{Mojgan Hamidi}

Department of Management, Economics and Accounting, Payame Noor University, PO BOX 19395-3697 Tehran, Iran

e-mail: hamidi.mojgan@yahoo.com

\section{Introduction}

Investigation of developments in organizational studies shows clearly that the issue of human in organization and management has been long considered by management scholars. This attention has increased day to day so that at present, human resources is called organizational customers. This means that in the modern era the requirement to respond to employees' basic needs in any organization is a top priority because achievement to organizational goals is dependent on addressing goals and logical and legitimate human resources (Abtahi, 1383). On the other hand, we are entering the third millennium when in Toffler's interpretation in his famous book „,The Third Wave", the evolution of human society has shifted from physical and capital-based power toward knowledge-based power resources. In the era of so-called information age, innovation, flexibility, speed of production redefinition, and development of new opportunities, can be considered the main sources of creating and sustaining competitive advantages. Therefore, companies increasingly rely on knowledge, skills and competencies of knowledge workers. These people, who were first called knowledge workers by Drucker in 1973, carry a knowledge on which organizations have no ownership. However, it is a powerful source that gives individuals the freedom to turn over and use their knowledge in different domains. Accordingly, maintaining knowledge workers in organizational level and preventing brain drain at national level can be among the requirements of HR managers with a more critical role in knowledge-based organizations.

Some scholars have proposed a comprehensive model of behavioral intentions which is widely used in illustrating the relationship between attitudes and behavior. Each individual's intentions for handling a particular behavior is the best predictor of that behavior. For example, the fastest and probably the most accurate way to determine whether an individual will resign in the future is asking another person to seek his intention to resign. Macro analyses of 34 studies on the employees' resignation which include more than 830 thousand cases has confirmed the validity of this method. Researchers found that behavioral intentions are better 


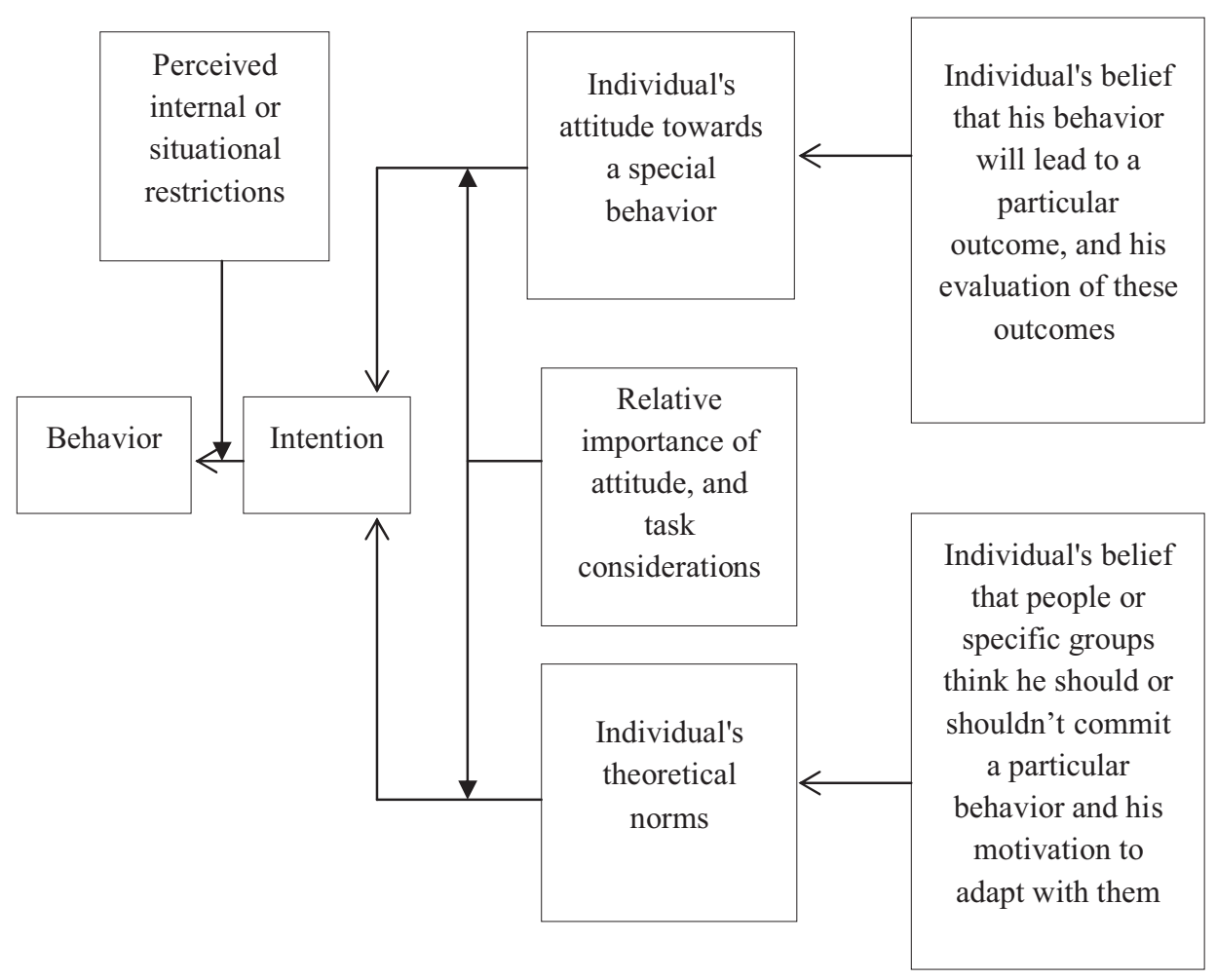

Fig. 1. Behavioral Intention Model

predictors of resignation compared to job satisfaction or satisfaction from work nature or organizational commitment (Steel and Ovalle II, 1992; quoted by Rezaian, 2001: 204).

Although the issue of individual intentions enables us to protect who will resign, it doesn't help to prevent their resignation. Therefore, it is essential to investigate employees' attitudes in order to understand their behavior. Behavioral intentions are influenced by attitudes toward a behavior as well as perceived norms regarding that behavior. Theoretical norms and attitudes are determined by specific personal beliefs (Rezaian, 2001: 204). Given that individuals' behaviors such as decision to stay or leave the organization are predictable and individuals' intention can be influenced by beliefs, attitudes, and norms, this study aims to investigate the relationship between work attitudes including job satisfaction and organizational commitment as well as believe in manager's reliability with knowledge workers' intention to leave in Iran's academic context.

\section{Theoretical Foundations of Research}

\subsection{The impacts of beliefs on attitudes and behavior}

Human's belief system includes a mental image of environment associated with him which is completed with probable causal relations. Beliefs are the result of direct observation and deduction from pre-known relations. For instance, everyone considers his smiling colleague as happy. Beliefs don't have a similar impact on attitudes regarding the extent of relation between attitudes and beliefs (ibid).
According to Table 1, an individual has a positive attitude toward a particular behavior (believes it) when he knows his behavior is accompanied by potential outcomes. When the individual believes that he can achieve a better position and the mental work pressure will be decreased, he more likely leaves his work. On the other hand, negative attitudes regarding turnover, will form when the individual believes it has negative outcomes such as loss of income source and position (Rezaian, 2001: 205).

Perceived social tasks for a particular behavior are called „theoretical norms". Theoretical norms are a function of beliefs which are called individual beliefs. According to these beliefs, the individuals consider others opinions and set their behavior based on their accepted norms. Therefore, according to Fisbein and Ajzen model (1975), theoretical norms and attitudes form behavioral intentions (ibid: 206).

\subsection{Trust}

One of the main beliefs of employees in the organization is trust among them and managers. High level of trust in organization leads to lower costs of assessment and other control mechanisms and creates self-control and intrinsic motivation in employees. Given that truest leads to organizational effectiveness and decrease of control and assessment costs, it is necessary to identify factors which establish trust (Hassan \& Hassanzadeh, 2004). Moreover, employees' organizational commitment is also influenced by this issue because if managers want to reduce employees' absenteeism and desertion, they should take actions to create positive attitudes among organizational members. However, if 
the organization suffers the prevailing atmosphere of distrust, this positive attitude will fade away (Khanifar et al., 2009: 4).

During the last decades, trust has been an important topic of study and its relation has been investigated with various occupational circumstances and outcomes (DeConinck, 2011: 617). Trust is a key element of organizational success and one of the essential factors for effective leadership along with the ability to create a vision; however, the best vision will not be effective without trust (Erturk, 2010: 410). Therefore, the researchers emphasize that employees should consider managers reliable (Hassan \& Hassanzadeh, 2004: 79). According to Kramer (1999) no clear definition of trust has been provided to be accepted by the consensus of all scholars; however, two common public and professional (institutional) definitions of trust can be presented. According to Mayer and colleagues (1995), trust is ,,the willingness of one party to be vulnerable to the actions of the other party based on the expectations that the trustee performs an important specific action regardless the ability to monitor or control the other one." From Sashkin's point of view (1990), trust in organization includes ,the confidence level employees feel toward the organization's management and the extent to which employees believe in what managers say." Lewicki and colleagues (2006) conclude that trust has two basic characteristics: positive expectations regarding the behavior of others and the willingness to accept vulnerability (Chughtai \& Bukley, 2009: 575). Trust in top managers is a conceptual measure of employees and their perception that eventually supervisors act based on employees' advantage. Based on studies, trust consists of two cognitive and affective dimensions: cognitive-based trust includes logical evaluation of the ability to perform requirements and obligations and hence reflects the reliability and confidence of individuals such as responsible and qualified performance background of superiors providing support for reliability. In contrast, affective trust is based on the quality of staff interactions with their superior and reflects superior's affective attachment and concerns toward subordinates (Erturk, 2010: 415-5).

According to these definitions, one of the problems of today organizations is lack of trust between employees and managers. Chavoshi (2007) emphasizes that in domestic organizations especially governmental agencies- there is a significant gap between employees and managers and their demands. Because of this gap, decisions usually face administrative challenges; employees are rigid in implementing decisions and in return managers don't trust them, neither let them participate in decision making processes all of which will lead to an atmosphere of distrust in the organization. As a result of distrust, some behaviors such as spreading rumors, conflicts, political behaviors, and low organizational work will emerge, taking too much energy from the organization while increasing costs.

Studies have shown that trust helps information division in organization which shares all people in organizational information, organizational commitment, and commitment toward decision making, organizational citizenship behavior, job satisfaction, management satisfaction, leader-member interaction, and attention to stay in organization (Hassan \& Hassanzadeh, 2004). Commitment to task and organization is feasible when the main objective is kept for individuals (Rezaian, 2001) and this is dependent on the trust among people. Moreover, recent studies have shown that employees' trust in their superior has a negative relation with their willingness to leave (Costigan et al., 2011: 74). One of the main outcomes of employees' high trust in managers is less absenteeism and resignation (Hassan \& Hassanzadeh, 2004: 107).

When employees have more trust in managers, their willingness to leave will significantly decrease. These results have been also confirmed in a meta-analysis by Bijlsma \& Koopman (2003) who show that trust-based relations between employees and organization leads to higher loyalty and less probability of their leave (Hemdi \& Nasurdin, 2006: 27).

\subsection{Work Attitudes}

Several studies have tried to investigate the relationship between employees' attitudes and work outcomes. Some of them have considered job satisfaction as a key attitude associated with employees' work behaviors such as job performance and turnover (Lock, 1976). Moreover, organizational commitment has been an important attitude predictor for employees' intentions and behaviors (Mowday, Porter, \& Steers, 1982). This study aims to investigate the relationship between job satisfaction, organizational commitment, and trust in managers with knowledge workers' intention to turnover.

Theoretical framework of this study is derived from Ajzen behavioral intention model that knows personal beliefs, attitudes, and norms as influencing factors on intention and decision to behave.

Based on this model, the researchers aim to investigate the relationship between attitude variables of job satisfaction and organizational commitment, and variables of knowledge workers' beliefs in managers' reliability with their intention to stay.

Porters, Steers, Mowday, \& Boulian (1974) have suggested that attitudes associated with organization may have more impacts on decision to stay compared to special work attitudes. Wiener and Vardi (1980) stated that organizational attitudes will probably have a stronger relation with organizational outcomes such as turnover, while the influence of work attitudes will be more significant on work outcomes such as performance. Moreover, Jackofsky and Peters (1983) explained that work turnover has a stronger relation with job satisfaction and organizational turnover has the highest relation with organizational commitment. They argue that work attitudes are associated with work outcomes and organizational attitudes are associated with organizational outcomes (Shore \& Martine, 1989: 626).

Several studies have confirmed the significant relationship between organizational commitment and employees' intention to 
leave (Ferris \& Aranya, 1983; Wiener \& Vardi, 1980). Other studies have also established a relationship between job satisfaction and intention to turnover. According to some researchers, overall job satisfaction is related to intention to turnover. Studies regarding satisfaction have reported a significant relation between intention to turnover and satisfaction from the nature of the work and reward and promotion (Shore \& Martin, 1989: 626).

Guest (2007) emphasizes that organizational commitment can be achieved through psychological contract which is focused on trust and attachment among people. Therefore, employees can be kept through job independence and internal satisfaction. In the framework of this psychological contract, organizational policies and procedures will affect job satisfaction, work-life balance, job security, and consequently decision to stay or leave (Wang, 2012:66).

Watson (1999) in his study on 7500 American workers found that human resource practices and trust in management have the strongest effect on commitment (Martin, 2011: 35).

Although all these studies have confirmed the difference of job satisfaction and organizational commitment in prediction of employees' intention and decision to turnover, Shore and Martine (1989) concluded in their study that the strong relation of organizational commitment with intention to leave compared to job satisfaction is significant in unprofessional employees, but their research didn't confirm it among professional employees. Moreover, Cushen and Thompson (2012) claimed that despite the current trend, skilled and technical employees can be simultaneously unsatisfied, non0sligned, and have a high performance too.

The present study helps in development of existing literature in two ways. First, in addition to work attitudes, the role of trust in managers is indicated regarding employees' intention to turnover. Second, research context provides a model in which the influence of beliefs, organizational and work attitudes on knowledge workers' intention to stay in Iran's academic context.

According to theoretical foundations, Ajzen's behavioral intention model, employees' turnover theories, findings of other researches, and also the researcher's innovation, theoretical model of research was provided in framework of path model to explain relationship between work attitudes and beliefs with knowledge workers' intention to turnover as Fig. 2.

Research hypotheses were formulated based on theoretical model as follows:

\section{Main hypotheses:}

Hypothesis 1. Knowledge workers' job satisfaction affects their organizational commitment.

Hypothesis 2. Knowledge workers' trust in management influences their intention to stay.

Hypothesis 3. Knowledge workers' organizational commitment influences their intention to stay.

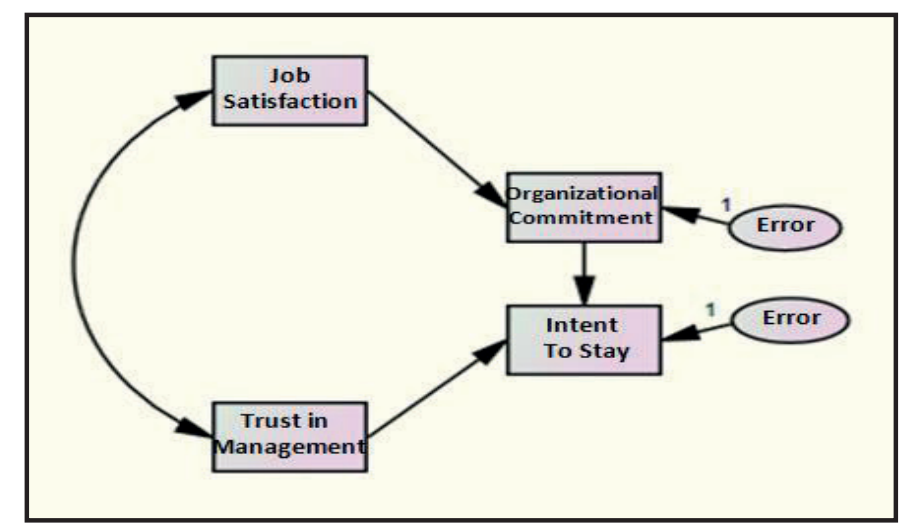

Fig. 2. Research Theoretical Model

\section{Secondary hypothesis:}

There is a significant difference between knowledge workers' intention to stay in governmental and non-governmental organizations.

\subsection{Research Methodology}

Since the purpose of the research is identifying non-experimental causal relations among organizational commitment, job satisfaction, trust in management and knowledge workers' intention to stay, the research approach is correlative (analysis of variables' relationship based on research objectives) and descriptive regarding data collection while it is practical given the aim and objective (Sarmad, Bazargan \& Hejazi, 2009: 90); this is clearly based on path analysis. Path analysis method is a generalization of muti-variable regression to formulate a clear causal model that is able to express observed correlations and relations logically. The goal of path analysis is to obtain quantitative estimates of causal relationships among a set of variables (Hooman, 2009: 45). In this research, trust in management, job satisfaction, and organizational commitment are considered as prediction variables; organizational commitment as mediators variable; and knowledge workers' intention to stay as criterion variable.

Statistical population of the study included all faculty members of South Khorasan universities and institutions of higher education which consisted of 660 participants based on these organizations' internal data. Sampling was done by stratified random method; All universities and educational institutions were assigned to two governmental and non-governmental categories and the sampling was performed randomly according to each category's size. Two methods were used to estimate sample size:

a) Cochran formula: Given that the population included 660 participants and with respect to $\% 95$ confidence, $\% 50$ of success rate and $\% 5$ error, the number of samples was 244 using Cochran formula:

$$
n=\frac{\frac{Z_{\frac{a}{2}}^{2}(P)(1-P)}{\square^{2}}}{1+\frac{1}{N}\left(\frac{Z_{\frac{a}{2}}^{2}(P)(1-P)}{\square^{2}}-1\right)}=\frac{384.16}{1.5805}=243.05 \cong 244
$$


b) Morgan sampling table which shows $n=244$ for selected population. According to these methods, 270 questionnaires were distributed among participants and finally 256 qualified questionnaires were collected and analyzed. Questionnaires were used as data collection tools. Therefore, Linz (2003) questionnaire was used to measure job satisfaction, Meyer, Allen and Smith (1993) questionnaire to measure organizational commitment, Tzafrir (2007) questionnaire to evaluate trust in management, and Hunt, Osborn and Martin questionnaire to evaluate intention to stay. For measurement of intention to stay, explanatory options were used while in other cases Lickert 5-item scale was selected.

To measure reliability of research tools, a primary sample including 30 questionnaires was selected as pre-test. Internal validity was estimated using Chronbach's alpha which was 0.824 for intention to stay. These numbers indicate that questionnaires have acceptable reliability. Questionnaires' validity as well as standard research tools were confirmed by experts and scholars.

\section{Findings}

Demographic characteristics of statistical sample shows that $66.8 \%$ of respondents were employed in governmental universities and educational institutions while $33.2 \%$ were employed in private sector; $35.2 \%$ had master's degree and $64.8 \%$ doctoral degree; $32 \%$ of respondents were female and $68 \%$ male; 9.4\% had work experience less than a year, 39.5\% between 1 to less than 5 years, $33.2 \%$ between 5 years to less than 10 years, $13.7 \%$ between 10 years to less than 20 years and $4.3 \%$ more than 20 years; regarding employment status, $15.6 \%$ were contract workers, $41 \%$ pact workers, $30.1 \%$ official-demo, and $13.3 \%$ official-employed.

\subsection{Model Estimation and Test}

After theoretical model establishment in the form of path model and evaluation of free and fix parameters, it is time to estimate and test model as well as analyze model's mirror and major indicators. Model test makes it clear if experimental data support developed theoretical model or not.

\subsection{Overall Analysis of Model (Overall fitness indicators)}

Three general classes of model fitness indicators include absolute, comparative and economic fitness indicators. In this section, the most important overall fitness indicators are investigated. The results are presented in Table 1.

\subsection{Separate Hypotheses Tests}

Since each model path is considered a hypothesis, the following table presents all hypotheses (paths) along with standardized estimations, significance, and dependent variable prediction.

According Table 2, all three main hypotheses of the research are statistically significant.

In the first hypothesis the effect of hob satisfaction on organizational commitment is 0.446 which shows a significant statistical difference with zero $(\mathrm{p}<0.05)$. According to standardized estimation, the dependent variable of organizational commitment can be predicted based on dependent variable of job satisfaction (\%44.6). Moreover, \%19.9 of observed distribution in organizational commitment can be explained by job satisfaction. The analysis is extensible for other hypotheses too.

Tab. 1. The results of model's overall fitness indicators

\begin{tabular}{|c|c|c|c|}
\hline Indicator & Amount & Acceptable range & The result of fitness indicator \\
\hline Relative Chi square (CMIN/DF) & 2.596 & $1-5$ & Model verification \\
\hline Significance $(P)$ & 0.075 & More than 0.05 & Model verification \\
\hline Bentler-Bonnet normalized fitness indicator (NFI) & 0.977 & More than 0.90 & Model verification \\
\hline Relative fitness indicator (RFI) & 0932 & Close to 1 & Model verification \\
\hline Incremental fitness indicator (IFI) & 0.986 & More than 0.90 & Model verification \\
\hline Tucker-Luis indicator (TLI) & 0.957 & More than 0.95 & Model verification \\
\hline Comparative fitness indicator (CFI) & 0.986 & More than 0.90 & Model verification \\
\hline Average square of estimation errors (RMSEA) & 0.079 & Less than 0.09 & Model verification \\
\hline HOELTER & 295 & More than 200 & Model verification \\
\hline
\end{tabular}

Tab. 2. Standardized estimation coefficients and dependent variables' prediction and explanation

\begin{tabular}{|c|c|c|c|c|}
\hline Hypothesis & Standardized estimation & Significance & Prediction (\%) & Test result \\
\hline Job satisfaction Organizational commitment & 0.446 & 0.000 & 44.6 & Hypothesis confirmation \\
\hline Trust in management Intention to stay & 0.340 & 0.000 & 34 & Hypothesis confirmation \\
\hline Organizational commitment Intention to stay & 0.327 & 0.000 & 32.7 & Hypothesis confirmation \\
\hline
\end{tabular}


Tab. 3. Groups Descriptive Data

\begin{tabular}{|c|c|c|c|c|}
\hline & & Number & Mean & SD \\
\hline \multirow{2}{*}{ Intention to stay } & Governmental & 171 & 3.29 & 0.9 \\
\hline & Non-governmental & 85 & $3 / 1$ & 1 \\
\hline
\end{tabular}

Tab. 4. Independent Sample Test

\begin{tabular}{lccccccc}
\hline & \multicolumn{2}{c|}{ Levene Test } & \multicolumn{3}{c}{ T-Test } \\
\cline { 2 - 7 } & Amount & Significance & T Amount & Degree of Freedom & Significance & Mean Difference \\
\hline The assumption of variance equality & 4.65 & 0.032 & 1.52 & 254 & 0.130 & 0.19 \\
\hline The assumption of variance inequality & & & 1.45 & 150.24 & 0.148 & 0.19 \\
\hline
\end{tabular}

Secondary Hypothesis Test: There is a significant difference between knowledge workers' intention to stay in governmental and non-governmental organizations.

According to Table 3, there is no significant difference between the means of two groups $(0.19)$ regarding intention to stay. However, these results are confirmed by inferential statistics. The results of T-test are presented in Table 4.

Given the significance number (0.032) of Levene test ( $\operatorname{sig}<0.05)$, the inequality of variances is resulted; therefore, T-test in the second row (variance inequality) is the basis of analysis. Based on significance number (0.148) of T-test ( $\operatorname{sig}>0.05$ ), there is no difference between knowledge employee's intention to stay in governmental or non-governmental organizations. Therefore, the secondary hypothesis of the research was not confirmed.

\section{Conclusion and discussion}

The present study aimed to investigate the predictability of knowledge workers' intention to stay based on their occupational attitudes and beliefs. According to findings, an important belief such as trust in management can predict intention to stay up to $34 \%$. On the other hand, employees' occupational attitudes have also the ability to predict knowledge workers' intention to stay. Based on the results of this study, dependent variable of organizational commitment (32.7\%) can predict dependent variable of intention to stay. Moreover, $10.7 \%$ distribution in intention to stay is justified and explained by organizational commitment. Job satisfaction can also influence intention to stay indirectly $(0.146)$ through organizational commitment. Accordingly, organization managers who have knowledge workers should try to keep them through increasing trust in management. In addition, it should be noted that managers' competencies will influence employees' trust. Considering this issue, particularly in assigning managers in intermediate levels that have a close relation with employees and also in selection of top managers, who decide of macro policies of the organizations is essential. Investigations on trust-based procedures regarding knowledge workers should be performed in future.
Organizational commitment is created hardly in knowledge workers and these people have a high probability of turnover. This means that knowledge workers are more committed to their occupation than a special organization. If these employees feel that they have an opportunity to develop their skills and powers in a specific organization, they will have commitment toward the organization. In present study, given the predictor variables, job satisfaction could act as organizational commitment predictor in this group (coefficient 0.446 ). In other words, the research shows that if an organization provides work conditions through supportive procedures s that knowledge workers have sufficient opportunity to balance their personal and occupational life and do their work properly in organizational context, they will handle initiative and show satisfaction and commitment.

According to the secondary hypothesis of the research there is no significant difference between knowledge workers' intention to stay in governmental and non-governmental organizations. This finding confirms our previous claim that knowledge workers are more committed to their job than a specific organization. Therefore, an organization will be successful in absorbing and keeping these employees that provides more organizational support compared to competitors and enables them to develop their skills; in other words an organization that satisfies these workers will be successful.

According to the results, multi-variable correlative coefficient of intention to stay (0.27) shows that dependent variable (intention to stay) can be predicted from independent variables that influence intention to stay up to $27 \%$. This is probably because of the fact that intention to stay is influenced by personal, organizational, and environmental factors such as personality, family conditions, salary, job nature and content, co-workers, market, and job alternatives. Given the importance role of human capital and resources, particularly knowledge workers, in organizational competiveness identification of these factors and prevention of brain drain in national level will be essential and should be investigated in future studies. 
Abtahi S. H. (2004) Human Resource Management. Tehran: Institute of Management Education and Research.

Bijlsma K., Koopman P. (2003) Introduction: Trust within organizations. Personnel Review, 32 (5), pp. 543-555. DOI: $10.1108 / 00483480310488324$

Chavoshi S. M. H. (2007) Investigating the relationship between emotional intelligence and trust between managers and their subordinates. Master's Thesis. Tehran University.

Chughtai A. A., Buckley F. (2009) Linking trust in the principal to school outcomes: The mediating role of organizational identification and work engagement. International Journal of Educational Management. 23 (7). pp. 574-589.

DOI: $10.1108 / 09513540910990816$

Costigan R. D., Insinga, R. C., Berman, J. J., Kranas, G., Kureshov, V. A. (2011) Revisiting the relationship of supervisor trust and CEO trust to turnover intentions: A three-country comparative study. Journal of World Business, 46 (1), pp. 74-83. DOI: 10.1016/j.jwb.2010.05.019

Cushen J., Thompson P. (2012) Doing the right thing? HRM and the angry knowledge worker. New Technology, Work and Employment, 27 (2), pp. 79-92. DOI: $10.1111 / j .1468-005 x .2012 .00285 . x$

DeConinck J. B. (2011) The effects of ethical climate on organizational identification, supervisory trust, and turnover among salespeople. Journal of Business Research, 64 (6), pp. 617-624. DOI: $10.1016 /$ j.jbusres.2010.06.014

Drucker P. F. (1973) Management: Tasks, Responsibilities, Practices. New York: Harper \& Row.

Ertürk A. (2010) Exploring predictors of organizational identification: Moderating role of trust on the associations between empowerment, organizational support, and identification. European Journal of Work and Organizational Psychology, 19 (4), pp. 409-441.

DOI: $\underline{10.1080 / 13594320902834149}$

Ferris K. R., Aranya N. (1983) A comparison of two organizational commitment scales. Personnel Psychology, 36 (1), pp. 87-98. DOI: $10.1111 / \mathrm{j} .1744-6570.1983 . t b 00505 . \mathrm{x}$

Fishbein M., Ajzen I. (1975) Belief, attitude, intention and behavior: An introduction to theory and research. Reading, MA: Addison-Wesl.

Guest D. E. (2007) HRM and the worker: towards a new psychological contract? In. "Boxall P., Purcell J., Wright P. M. (eds). The Oxford handbook of human resource management." Oxford: Oxford Press. pp. 128-146.

Hemdi M. A., Nasurdin A. M. (2006) Predicting Turnover Intentions of Hotel Employees: the Influence of Employee Development: HRM Practices and Trust in Organization. Gadjah Mada International Journal of Business, 8 (1), pp. 21-42.

Hooman H. A. (2009) Structural Equation Modeling and software application. Tehran: SAMT publication.

Hunt J. G., Osborn R. N., Martin H. J. (1981) A multiple influence model of leadership (Technical report no. 520), Alexandria, Virginia: U.S. Army Research Institute for the Behavioral and Social Sciences.

Jackofsky E. F., Peters L. H. (1983) Job turnover versus company turnover: Reassessment of the March and Simon participation hypothesis. Journal of Applied Psychology, 68 (3), pp. 490-495. DOI: $10.1037 / 0021-9010.68 .3 .490$

Khanifar H. M. S. M., Jandaghi G. R., Zarvani N. (2009) Examination the relation between trust and organizational commitment (In agriculture and education organizations in Qom province). Journal of Public Administration, 1 (2), pp. 3-18.
Kramer R. M. (1999) TRUST AND DISTRUST IN ORGANIZATIONS: Emerging Perspectives, Enduring Questions. Annual Review of Psychology, 50, pp. 569-598.

DOI: $10.1146 /$ annurev.psych.50.1.569

Lewicki R. J., Tomlinson E. C., Gillespie N. (2006) Models of interpersonal trust development: Theoretical approaches, empirical evidence, and future directions. Journal of Management, 32 (6), pp. 991-1022. DOI: $\underline{10.1177 / 0149206306294405}$

Linz S. J. (2003) Job satisfaction among Russian workers. International Journal of Manpower, 24 (6), pp. 626-652. DOI: $\underline{10.1108 / 01437720310496139}$

Lock E. A. (1976) Nature and cases of job satisfaction, Handbook of industrial and organizational psychology. Chicago: Rand McNally. pp. 1297-1349.

Martin M. J. (2011) Influence of human resource practices on employee intention to quit. (Unpublished doctoral dissertation.) Faculty of Virginia Polytechnic Institute and State University.

Meyer J. P., Allen N. J., Smith C. A. (1993) Commitment to the organizations and occupations: Extension and test of three-component conceptualization. Journal of Applied Psychology, 78 (4), pp. 538-551. DOI: $10.1037 / 0021-9010.78 .4 .538$

Mowday R. T., Porter L. W., Steers, R. M. (1982) Employee-organization Linkages: The psychology of commitment, absenteeism and turnover. New York: Academic Press.

Porter L. W., Steers R. M., Mowday R. T., Boulian P. V. (1974) Organizational commitment, job satisfaction, and turnover among psychiatric technicians. Journal of Applied Psychology, 59 (5), pp. 603-609. DOI: $10.1037 / \mathrm{h} 0037335$

Rezaian A. (2001) Management of Organizational Behavior. Tehran: SAMT publication.

Mayer R. C., Davis J. H., Schoorman F. D. (1995) An Integrative Model of Organizational Trust. Academy of Management Review, 20 (3), pp. 709-734. DOI: $10.5465 / \mathrm{amr} .1995 .9508080335$

Sarmad Z., Bazargan A., Hejazi E. (2009) Research Methods in Behavioral Sciences. Tehran: Agah Publication.

Sashkin M. (1990) The Managerial Mirror: Trainer Guide. Seabrook, MD: Duchochon Press.

Sekaran U. (2011) Research methods in management (Sabeai and Shirazi, Translators). Tehran: Center for Public Management.

McFarlane S. L., Martin H. J. (1989) Job Satisfaction and Organizational Commitment in Relation to Work Performance and Turnover Intentions. Human Relations. 42 (7), pp. 625-638.

DOI: $\underline{10.1177 / 001872678904200705}$

Toffler A. (1980) The Third Wave. New York: William Morrow and Company.

Tzafrir S. S., Gur A. B. A. (2007) HRM Practices and Perceived Service Quality: The Role of Trust as a Mediator. Research and Practice in Human Resource Management. 15 (2). pp. 1-20.

Wang Y-H. (2012) Recruitment and Retention of Knowledge Workers in Taiwan's High Technology Industry. (Unpublished doctoral dissertation.) Cardiff University.

Watson W. (1999) Work USA 2000: employee commitment and the bottom line. Bethesda, MD: Watson Wyatt. http://www.watsonwyatt. com/research/printable.asp? id=W-304.

Wiener Y., Vardi Y. (1980) Relations between job, organization, and career commitment and work outcomes - an integrative approach. Organizational Behavior and Human Performance, 26, pp. 81-96.

Hassan Z. M., Hassanzadeh H. (2004) Inter-organizational trust and check the status of executive. Journal of Management Culture. 2 (7). 